\title{
Social Justice: A Missing, Unelaborated Dimension in Humanitarian Engineering and Learning Through Service
}

\author{
Jon A. Leydens \\ Colorado School of Mines \\ Golden, CO, USA \\ jleydens@mines.edu
}

\author{
Juan C. Lucena \\ Colorado School of Mines \\ Golden, CO, USA \\ jlucena@mines.edu
}

\begin{abstract}
Negotiations between engineering and non-engineering perspectives are central in humanitarian engineering and learning through service initiatives, and these negotiations inevitably include dimensions of social justice. But what frameworks guide engineers through such negotiations? To date, in published scholarship, social justice has played little to no role in providing structure for work in humanitarian engineering and learning through service. Yet structure is needed to think and act systematically on the social justice dimensions inherent in humanitarian engineering and learning through service initiatives and practices. Drawing from multiple data sources, including interviews with engineering education faculty on the barriers and opportunities to integrating social justice dimensions in such initiatives, we provide a social justice definition and criteria that serve as flexible guidelines for humanitarian engineering and learning through service initiatives. Grounded in a synthesized definition of social justice, the social justice criteria can guide engineers to recognize and map human and non-human, engineering and non-engineering components in problem definition and solution-with social justice at the core. Along with other benefits, these criteria can act as a foundation from which to launch, evaluate, and improve on humanitarian engineering and learning through service work, serving as a vehicle for project initiation, reflection, and self-critique.
\end{abstract}

Index Terms - humanitarian engineering, learning through service, social justice criteria, social justice applications.

With great power, comes great responsibility. Engineering has the power to transform the world: the water we drink, air we breath, infrastructure we use for energy and transport, medicines we use for healing, way we conduct warfare and peace, and much, much more. Given the power of engineering, we need an engineering education that is tailored to the great responsibility engineers will assume in transforming life in the 21st century and beyond. Engineers design, build and operate simple and complex systems, capable of affecting the lives of millions of people, as well as the allocation of resources (e.g., water), opportunities (e.g., access to work and commerce), risks and harms (e.g., flooding), and how diverse social groups receive these differently. Consider the devastation that took place in New Orleans in 2005. When the levees - an engineered infrastructure system - failed, one can see that when a natural hazard, like Hurricane Katrina, interacts with engineered systems on which people's lives depend, the consequences are different for different groups of people. In the case of Katrina, the failure of the levees in New Orleans affected the poor (mostly black) and those with disabilities more than any other social groups, taking away their resources (e.g., property), opportunities (e.g., to rest and replenish at home so one can be a functional member of society) while exposing them to more risks and harms (e.g., disease, drowning, homelessness). ${ }^{1,2}$ 


\section{INTRODUCTION}

Engineers' potential for widespread public and private good or harm is substantial. In that sense, engineering and social justice (SJ) go hand in hand. Their interrelation becomes particularly evident when engineers engage a community in ways that attempt to bring about explicit sociotechnical transformations to the lives of people standing in different power relations with engineers, such as via humanitarian engineering and service learning/learningthrough-service (HE/LTS). When engineering designers conceptualize a new elementary school playground in a poor neighborhood, for instance, they are also addressing systemic injustices (such as the prevalence of such playgrounds at private schools and the relative lack of them at public schools). Thus, the word sociotechnical is particularly fitting: engineering design does not occur in a vacuum, but in a social context that shapes (and is ultimately shaped by) the design process and resulting product, from problem definition to solution. That is, as applied to the levees example, a given levee design features technical dimensions for the levee itself (e.g., buckling under pressure given specific height and width), but the technical dimensions are sociotechnical, at no point divorced from the social realities in which the levee will be used (who gets to be in neighborhoods right next to levees that might not be tested for flooding after a Category 5 Hurricane; who pays for them; who maintains them; who sets the building codes for the levees, etc.).

Despite the recognition that engineering designs and systems can substantially influence public and private health and well being, the engineering-SJ connection is rarely made explicit in either engineering education or practice. More specifically, SJ as a guiding construct in HE/LTS published research is largely invisible, whether HE/LTS work occurs in curricular, co-curricular, or extracurricular contexts. For example, a keyword search for "social justice" in this journal yielded only one paper, ${ }^{3}$ where the term was not defined but used openly when surveying students about their SJ interests. This single occurrence is not surprising as the communities that have developed the ideas of service learning (mainly the Community Engagement division at American Society for Engineering Education (ASEE)) and social justice (mainly the Engineering, Social Justice and Peace Network) in engineering education have grown separately. This paper aims at building a conceptual bridge between these communities in order to provide a common framework-definition and criteria for problem definition - that would lead to effective collaborations. Our forthcoming book, Engineering Justice: Transforming Engineering Education and Practice, seeks to expand this bridge to accentuate engineering-SJ connections in three components of the engineering curriculum: the engineering sciences, design, and humanities/social sciences. Whereas our book focuses on applications for both engineering practitioners and educators, this article centers on the latter group. Practitioners interested in applications are invited to consult our book and other sources. (e.g., 4,5)

Also, at the ASEE annual conference, sessions or papers with the phrase social justice in the title indicate a strong thematic focus on SJ, but such papers are rare. At recent ASEE annual conferences, there were no sessions and few such papers in (number in parenthesis) 2014 (1), 2013 (0), 2012 (0), 2011 (2), 2010 (1), 2009 (0), and 2008 (0). To be fair, however, some research imbued with SJ concepts and content has appeared at ASEE with the words social justice noted explicitly in the paper or implicitly in the paper's thematic focus, such as $6,7,8,9$

When SJ is present in engineering education research, it often surfaces indirectly, is misinterpreted, or can be oversimplified. For instance, it can be equated with compassion, service, doing the right thing, being ethical, or, in the cases of closest approximation to a definition, as the "P" for People in the sustainability triangle of Profit, Planet and People10. 
Hence, when SJ is present explicitly, it is rarely defined or elaborated. To further complicate matters, HE/LTS practices can be motivated by an engineering mindset - the desire to help and persistence to do it - which can blind practitioners to how their actions, although well intentioned, actually reinforce social injustices. Much has been written to critique the desire to help, especially when manifested in short-term missions and charity work by student teams $11,12,13$. Yet not much has been published that would help HE/LTS efforts to move beyond the desire to help and to think and act systematically on the social justice dimensions of service and community-engagement practices. This paper aims in that direction.

\section{METHODS}

To better understand the potential bridges between HE/LTS initiatives and SJ, we draw from multiple sources of qualitative data. First, the authors draw from five years of research meetings, initially stimulated by a National Science Foundation grant, that have led to multiple publications on engineering-SJ connections, community development, and the intersection of those two topics (e.g., ${ }^{12,14,15,16}$ ). As part of that research, we have conducted over a dozen research interviews with engineering education faculty-including faculty in HE/LTS initiatives - from the U.S. and Canada on barriers and opportunities to integrating SJ in engineering contexts. The interviews have informed our understanding of cognitive, affective, institutional, and other barriers and opportunities to SJ integration in engineering. Second, we draw from a literature review on HE/LTS initiatives and engineering-SJ connections. Our third data source includes regular interactions with some of the most innovative non-government organizations (NGO) that employ engineers and work with us facilitating engineering design teams (e.g., Nokero, iDE, Edge of Seven, Bridges to Prosperity, EWB-USA), but who lack frameworks to conceptualize SJ in problem definition. Those interactions stem from our leadership roles in our campus' Humanitarian Engineering Program, wherein one author serves as Director (Lucena) and another author as member of the Program's Curriculum Committee (Leydens). Finally, we draw here from reflections on a two-year collaborative design of the course "Engineering and Social Justice" (2009-2011), from teaching that course annually since 2011, and from delivering social justice workshops to engineering educators.

\section{WHAT SOCIAL JUSTICE IS...NOT}

This paper directly addresses the lack of a clear definition and elaboration of SJ as a construct that can inform and give structure to work in HE/LTS. But before doing so, it is important to address what SJ is not. First, SJ is not equivalent to engineering ethics as codified in the engineering codes. While some classroom textbooks make references to distributive justice, ${ }^{17}$ no code of ethics makes reference to any kind of justice, perhaps because these codes are manifestations of historical processes that have placed engineers as "servants of a system" dominated by for-profit corporate interests. ${ }^{18-19}$ In such systems, loyalty to the employer, and, in the best case, a concern for public safety trumped any concern for justice. In his history of how the American engineering profession lost its battle for professional autonomy to corporate interests, Edwin Layton reminds us that the adoption of codes of ethics by engineering societies in the early 20th century had more to do with seeking professional status while reminding engineers that they "should consider the protection of a client's or employer's interests [their] first professional obligation" (p.70) ${ }^{20}$ One hundred years later, codes of ethics have come to include "sustainable development," in the best cases, but do not reference social justice. Social justice considerations move ethics beyond microethics (which 
focuses on issues such as employer loyalty) and provide a salient opportunity to enact macroethics, as we explain below, by accentuating broader sociotechnical concerns about distributions of resources and opportunities as well as risks and harms in order to enhance human capabilities.

Second, SJ is not equivalent to compassion or doing the right thing. Compassion is appealing to engineers, especially those committed to the success of HE/LTS initiatives, because it challenges us to ask HOW we can solve the immediate need or problem of people, for example a homeless community or one lacking water, suffering from specific circumstances. In short, it appeals to engineers' strong sense of identity as problem-solvers. The desire to help and the persistence to make change happen, as Riley has pointed out, can bolster SJ efforts. ${ }^{21}$ Research on the origins of motivation to be involved in, for instance, Engineers Without Borders projects, identifies a desire to help and to learn. ${ }^{22}$ However, acting through compassion does not challenge us to ask WHY these problems exist and persist in the first place, and how we might address via engineering designs, models, etc. systemic forces that allow these problems to persist. Compassion does not invite us to question and address the forces that create homelessness (e.g., gentrification, unaffordable housing, manipulations of mortgage markets) or keep a community without potable water (e.g., policies that benefit energy or mining companies' use of water). Compassion addresses symptoms but not root causes. Compassion is convenient because we can do it through established mechanisms that do not challenge the status quo (e.g., charities, volunteer work, philanthropy), while SJ work challenges us to question our assumptions, our own privileges, our own positions in the systems of power, and the structures behind those power systems.

Also, SJ is not equivalent to service. Most service is driven by compassion and while it is a significant improvement over "helping" ( see $^{12}$ ), it does not systematically address inequalities in distributions of resources or opportunities. Service is a good start because it can make privilege and the end results of inequality (e.g., poverty, homelessness) visible to our students. Yet service initiatives do not provide criteria for them to begin defining engineering problems to deal with social justice issues.

In this paper, we argue for a clear, classroom-tested definition of SJ and for the resulting SJ criteria that make SJ useful in guiding our efforts in HE/LTS work. These criteria, we propose, can act as a foundation from which to launch, evaluate, and improve on HE/LTS work, serving as a vehicle for project initiation, reflection, and self-critique. We also argue that SJ needs to be made central in HE/LTS initiatives because it provides needed benefits, elaborated on at the end of this paper. To understand these benefits, we need a clear definition and elaboration of how SJ criteria can inform HE/LTS initiatives.

\section{SOCIAL JUSTICE DEFINITION}

As Riley has adeptly pointed out, definitions of SJ are dynamic and contested. ${ }^{21}$ However, many definitions have similar elements, and we have drawn from both SJ research and pedagogical practice to tailor a definition suited for the engineering profession and engineering education. This classroom-tested definition has evolved over several years from multiple iterations of teaching a course on Engineering and Social Justice and from multiple research publications on engineering-SJ connections (e.g., $\left.{ }^{16}{ }^{23}\right)$. In relationship to engineering, we define SJ as engineering practices that strive to enhance human capabilities (goal) through an equitable distribution of opportunities and resources while reducing imposed risks and harms (means) among agentic citizens of a specific community (a unique synthesis from ${ }^{24,25,26,27}$ ). 
This definition evolved from earlier forms, which did not sufficiently emphasize human capabilities. Our definition emerged by taking a well-established definition of distributional social justice (p. 18) ${ }^{24}$, which led many of our students to ask the question, "What are the distribution of resources, opportunities and the reduction of risks and harms for?" In short, students were challenging us to seriously think about "what is SJ in engineering for?" Adopting Nussbaum's Human Capabilities approach to $\mathrm{SJ}^{27,}{ }_{26}$, 29 , we are able to answer our students and challenge them to develop designs (or analyses or models) that are socially just in order to enhance human capabilities.

\section{SOCIAL JUSTICE CRITERIA FOR HE/LTS INITIATIVES}

One major dimension of SJ in engineering contexts needs to be mentioned up front, as it runs through each of the SJ criteria below: problem definition. In fact, one of the primary benefits of these criteria is that they enable us to expand the problem definition phase in HE/LTS initiatives, to encompass a broader yet still manageable scope. The old saying that a problem well defined is half solved may be exaggerated, but the importance of problem definition remains today: what we put into the problem definition, what we leave out, what we emphasize or de-emphasize, whose perspectives are allowed to enter and whose are left out, all shape the overall effectiveness of the final design.

Yet we face a significant challenge, as US engineering education creates and reinforces a dominant image of the engineer as problem solver, not as problem definer, even though engineering work always requires engineers to be both. Gary Downey has identified the root of this problem in the separation and hierarchy that exists between technical and nontechnical curricula in US engineering programs. ${ }^{30}$ Here the technical domain is exclusively defined in terms of math- and science-based problem solving, as currently taught through the repetition of hundreds of textbook problems reinforced by more of the same during midterm and final examinations. (One of the authors has for the past several years asked senior-level undergraduates to estimate the number of (decontextualized, pre-defined) problems that they solve throughout their 4-5-year undergraduate program, and the resulting data ranges lead them to the realization that, in fact, they have become largely close-ended problem solvers.) Meanwhile, ever since Sputnik, design and all non-technical elements of the curriculum, such as liberal arts courses, have lived at the periphery and are viewed as a complement, in the best of cases, but often as a distraction. Yet Downey reminds us that in engineering work, problem solving always includes problem definition and the latter always involves negotiations between engineers' and non-engineers' perspectives:

In carrying out their work, engineers necessarily negotiate and re-negotiate the definitions of technological problems both among themselves and with nonengineers. Accordingly, one potentially promising way of remapping the jurisdiction of engineering work to adapt effectively to the challenges of the present may be to redefine engineering work in terms of both problem solving and problem definition. (p. 590) ${ }^{30}$

These negotiations between engineering and non-engineering perspectives are central in engineering for social justice work, where engineers sit with non-engineers (e.g., communities, government and NGO officials, social workers) to determine what constitutes an equal or fair distribution, what resources and opportunities should be considered, what risks and harms are acceptable, etc. If HE/LTS programs and initiatives are to incorporate social justice as a key dimension, as we hope they do, they need to take the challenge of 
negotiation seriously. Yet, as far as we know, engineers have no framework to guide them through these interactions. Grounded on the above definition of SJ, we propose here criteria aimed at guiding engineers to recognize and map human and non-human, engineering and non-engineering elements involved in problem definition and solution with social justice at the core. Although each criterion by itself is important, as we explore below, the criteria are interconnected. The six SJ criteria include

- listening contextually

- identifying structural conditions

- acknowledging political agency/mobilizing power

- increasing opportunities and resources

- reducing imposed risks and harms

- enhancing human capabilities.

\section{A. Listening contextually}

The ability to listen contextually is integral to the success of HE/LTS projects and to the enactment of SJ. Here we explain the difference between basic and contextual listening, how the latter relates to HE/LTS work, and why contextual listening is a vital prerequisite in working toward SJ.

Basic listening "refers to hearing or paying attention to the verbal and nonverbal messages of any speaker" and "is framed as a dyadic process of speaking (output) and hearing/receiving information (input)" (p. 124). ${ }^{15}$ By contrast, contextual listening is a

multidimensional, integrated understanding of the listening process wherein listening facilitates meaning making, enhances human potential, and helps foster community-supported change. In this form of listening, information such as cost, weight, technical specs, desirable functions, and timeline acquires meaning only when the context of the person(s) making the requirements (their history, political agendas, desires, forms of knowledge, etc.) is fully understood. (p. 125) ${ }^{15}$

Contextual listening is well suited to and can bolster chances of success in HE/LTS work. HE/LTS project teams need to know as much as possible (given time and other constraints) about a given community's prior community development projects, about barriers and opportunities to trusting people from outside the community, about cultural realities and perceptions, about how community desires, forms of knowledge, and social locations inform their perceptions of the project, the collaboration, and the collaborators.

\section{A.1 Classroom tools}

In the classroom, a contrast in case studies can help illustrate ineffective and effective contextual listening: Bhutan vs. Waste for Life. A group of designers interested in assessing the economic and technical feasibility of bringing renewable energy storage using hydrogen to remote communities in Bhutan shows a lack of contextual. ${ }^{31}$ Although one of the authors of that feasibility study lived in the country for many years and the authors acknowledge the importance of engaging community perspectives, there is no indication such engagement occurred. At no point are any community-generated perspectives or needs mentioned or addressed. So while a clear community (economic and energy) need is established, the 
proposed solution has not been situated within the actual contextual circumstances of the community - that is, whether they frame the problem definition similarly, whether the solution addresses the problem as they experience it every day, and whether they can-and are motivated to-maintain the proposed energy system. ${ }^{31}$

By contrast, contextual listening was enacted with Waste For Life (WFL), a group of mostly engineers who among other projects engaged local community members in Buenos Aires, Argentina in 2007 and 2008. ${ }^{5}$ WFL was created "to provide access to scientific knowledge and technology, usually circumscribed by privilege, to people living on society's margins...[and] to open up pathways towards autonomy and genuine economic security for people who need it most-those living at the intersections of waste and poverty". 32 WFL project leaders recognized that contextual listening is a vital prerequisite in working toward SJ. Hence, they focused on remaining as unaffiliated as humanly possible while building relationships with a variety of community members. In doing so, they recognized that the quality of listening is directly proportional to the quality of trust. Although trust can be compromised by multiple factors outside our control - the community's prior experiences with community development projects, cultural barriers, and more-they focused on those factors they could influence. To build trust, they spent multiple months talking with local community members, asking questions, avoiding explicit affiliation with any one group, and trying to understand community desires and existing forms of knowledge. They used a threepart method, which involves contextual listening and other criteria: 1) they created WFL and fully acknowledged the fact that they listen from the vantage point of privileged academic and other professionals from the global North, 2) they listened to highly varied community perspectives on the structural conditions that create and maintain poverty as well as on possible opportunities to transcend it, 3) their listening facilitated a mapping of political agency and ways to mobilize power, as described below. All three of these occurred prior to proposing any technical solutions to community dilemmas.

In sum, by contrasting these two case studies, our students have realized that effective contextual listening augments the probability of establishing trust with community members. Furthermore, trust is a necessary precondition to understanding actual community desires, which itself is a necessary precondition to identifying HE/LTS solutions that are feasible technically, financially, and culturally. Together, those factors increase the possibility of enacting SJ.

\section{A.2 Project tools}

To ground these abstract ideas in our practice, we have proposed in previous research a method called Problem, Definition, and Solution (PDS), the purpose of which is to obtain a better understanding of a given community's location, knowledge, and desires (LKD). ${ }^{15}$ PDS emanated from Downey's commitment to listening and his research on technical controversies. ${ }^{33,34,35}$ PDS served as a mechanism for listening to and positioning multiple human perspectives yet not giving epistemic priority to one over another. As applied to contextual listening, PDS features specific actions:

1. Mapping perspectives by identifying three key elements for each stakeholder: location, knowledge, and desires.

2. Analysis and assessment of the implications of proposed solutions for each perspective. 
3. Mediation and perhaps reconciliation of contrasting definitions of problems and solutions for the perspectives involved.

4. Considering how shifting one's perspective might contribute to achieving a solution acceptable to all. (p. 141)

To use PDS, an understanding of LKD is necessary. Using the Bhutan and WFL case studies, our students have learned to map engineering perspectives with respect to the communities that these engineers are trying to serve. Faculty can invite students to do likewise with these or other case studies related to engineering in community development. To learn about social location or position, students look at issues such as "wealth, power, status gender, family, and ethnic background" (p. 140). ${ }^{15}$ Location analyses help them see what historical, cultural, ideological, familial, and personal dimensions catalyze or prohibit involvement in community development projects (p. 141). ${ }^{15}$ So after reading the case studies closely, we invite students to map engineers' and communities' social location by answering questions like, where are these engineers located with respect to communities (e.g., universities, research centers, NGOs)? Where do these engineers and community members come from (e.g., family background, socio-economic class, educational background)? How did these engineers and communities become involved (e.g., were engineers invited by the communities? are engineers writing a paper without the community's knowledge? did they live in the community?)?

To map knowledge, we invite students to ask what forms of knowledge diverse intraand extra-community actors hold that shape a shared community-supported goal. Knowledges might be formal and informal, experiential and analytical, expert and nonexpert, written or oral, scientific and non-scientific, tacit and codified (pp. 140-141). ${ }^{15}$ Knowledge mapping processes also provide an opportunity to challenge the primacy of engineering knowledge or at a minimum to recognize its limitations in HE/LTS contexts. With respect to the two case studies above, students mapped forms of knowledge by answering questions such as, what forms of formal knowledge (obtained in school and certified by credentials) do the engineers have vis-à-vis community members? What forms of informal knowledge (obtained by lived experiences, oral traditions, trial and error) do the engineers have vis-à-vis community members? How did each constituent come to have some forms of knowledge but not others?

To map desires, we challenge students to identify engineers' and diverse community desires and to recognize how they align with larger community struggles and aspirations, as well as with HE/LTS project teams' own desires (p. 141). ${ }^{15}$ With respect to the two case studies above, students mapped desires by answering questions such as, what do the engineers in each case want (e.g., advancing promotion and tenure through publication? feeling good about themselves by applying engineering to a community project? to listen well enough to understand a rich plurality of community perspectives?)? What do the communities want (a different source of energy? an increase in income? a more diversified local economy?, etc.)?

To understand how listening contextually yields crucial insights into LKD, we recommend that HE/LTS faculty and students use the tools in the chapter on Listening, especially section 5.8 and the accompanying exercises (43 and 44) in Engineering and Sustainable Community Development (pp. 140-142). ${ }^{15}$ 


\section{B. Identifying structural conditions that give rise to needs}

Contextual listening, done well, often leads us to identify the nature of structural conditions that give rise to community needs. Structural conditions could include economic, cultural, or other conditions that enable or constrain community aspirations. For instance, we have written elsewhere about a Biology in Engineering course in the Biological and Agricultural Engineering Department at Louisiana State University (LSU), wherein students design playgrounds for area public schools. ${ }^{23}$ The course instructor emphasizes contextual listening by positioning listening as an explicit course objective anchored by active listening instruction and practice. For example, students listen to community perspectives in a tripartite iterative process by 1 ) interacting with multiple community partners in the school community (including one-on-one tutoring of students for eight weeks), 2) formally reflecting on those interactions (via written assignments), and 3) investigating and acting on how those interactions and reflections inform their playground design. One major objective of such listening was relationship building to earn community trust. Why was trust so vital? Trust matters because the overarching goal is for students to design a playground that, in the instructor's words, "reflects the soul of the community" (p. 22). ${ }^{23}$ To do so, students must learn about play from students, which requires not just observations but getting to know students and earning their trust so they communicate what they really think and feel. Trust is also vital since student and school community feedback on evolving designs informs the design process and product. And as we noted in summarizing the instructor's description, "although [the LSU] students initially do not fully appreciate what tutoring a student has to do with engineering design, they generally finish the course recognizing that their interactions within the school community and their reflections clearly informed and improved their design choices" (p. 22). ${ }^{23}$

\section{B.1 Project or classroom tools}

Learning about the soul of a community inevitably leads to insights regarding the structural conditions that give rise to community needs. For instance, in the case of the LSU students, they identified diverse structural conditions. First, most of them attended private K-12 schools, and they report bringing preconceptions about the quality of public schools and their students. However, once they see how hard the school community and students work, they realize that student performances are shaped by other missing structural conditions - collegeeducated parents, ample school supplies, access to playgrounds, technology, and other resources they took for granted. After realizing they took these resources for granted, they need to overcome-via reflective writing - a sense of guilt rooted in their own (often previously unconscious) social class experience of privilege. One reflective writing approach we have used is a three-column log, where the first column describes, as factually as possible, what the student observed and heard when interacting with various community members on certain dates; the second column describes their personal and SJ reflections on those observations and what was heard, and the third column lists practical ideas on how the design or model might account for the insights that emerged from the observations and/or reflections. This classroom tool can help students identify structural conditions and work through guilt and other issues.

Awareness of structural conditions also emerges from course activities, such as learning how the 1954 Brown vs. Board of Education Supreme Court decision influenced racial integration. Such structural conditions help them understand why so many public schools lack playgrounds and other resources. An awareness of structural conditions 
encourages students, both at LSU and in all HE/LTS projects, to ask, "What can we do to address these conditions in our design?" (p. 23). ${ }^{23}$ In that sense, design for SJ foregrounds structural conditions so, whenever possible, such conditions in HE/LTS initiatives are integrated into the design problem definition and solution.

In the case of WFL, structural conditions were at the core of their initial listening process. Drawing from the work of Franklin, ${ }^{36}$ WFL project leaders asked-prior to launching their project - questions to elicit a clearer picture of structural conditions, such as, who benefits and who pays/suffers from the status quo-economically, environmentally, and in terms of broader social impacts? But they did not stop with decontextualized research. In face-to-face encounters in Buenos Aires, they interviewed dozens of local community members, to better understand

- What existing and future structural conditions could promote or hinder the cartoneros' cooperatives' autonomy and self-sufficiency?

- What materials were locally available? What products could be produced?

- How could cartonero cooperatives sustain any production and business over the long term? (p. 43). ${ }^{5}$

We invite you to challenge your students to ask and answer similar questions as related to their specific HE/LTS projects. Results of the WFL interviews with individual and cooperative cartoneros, with potential manufacturers, and with government agencies are described in the next section.

\section{Acknowledging political agency and mobilizing power}

A common result of contextual listening and attentiveness to structural conditions that undergird community needs is the awareness that both within and outside the community, diverse amounts and forms of social power exist. For example, when working with communities, engineers need to be attentive to the power difference that might exist between men vs. women or Christians vs. non-Christians or the power difference between a multinational corporation who can influence local politicians vs. a community co-op that cannot. As research on design for social justice has noted, "It merits reiterating that all technology — and hence design — serves some interests over others - that whether or not it is made explicit, technology design provides opportunities and resources for some, and contributes to increased risks and harms, usually for others" (p. 13). ${ }^{23}$

Given the inherently sociotechnical nature of technologies we design, it is important to be attuned to multiple aspects of political agency and methods of mobilizing power. In terms of political agency, we first need to recognize that what Riley calls engineers' "desire to help... and persistence to do it" (p. 39) ${ }^{21}$ is both an important motivation for HE/LTS work as well as a mindset worthy of critique. Riley notes that engineers frequently hold a desire to use their knowledge to help people and have the persistence to see their projects to completion. ${ }^{21}$ The importance of that mindset - a vital element in enacting SJ-is grounded in the fact that without such a catalyst, students and faculty may not be interested or become involved in HE/LTS initiatives in the first place. In short, those good intentions can motivate student engagement.

The mindset is also worthy of critique because, by itself, it may overlook several critical dimensions of HE/LTS initiatives (for a more detailed critique of the engineering-tohelp mindset, see ${ }^{12}$ ). Here we consider select dimensions by examining in some detail WFL's approach to HE/LTS. The engineers involved in this approach actively acknowledged 
political agency and created opportunities for mobilizing power. As noted above, WFL sought to work toward reducing poverty, increase environmental responsibility, innovate with reusable materials, and enact SJ. $^{5}$ After several months of relationship-building and community engagement activities, WFL project leaders eventually investigated the possibility of reusing recycled materials to help lift individuals, families and others out of poverty. However, before they worked to determine whether this project was technically, socially, and environmentally feasible, they first mapped the social landscape.

\section{C.1 Project or classroom tools}

Their first act of acknowledging political agency consisted of identifying the effects of the historical and socio-economic context on cartoneros in Buenos Aires. The cartoneros (literally, "cardboard pickers") (p. 48) ${ }^{5}$ retrieve waste (especially cardboard) that can be sold to recyclers. The demand for such work stemmed from structural (in this case socioeconomic) conditions. After the 2001 economic crisis in Argentina, unemployment increased dramatically, leaving many families to scavenge for a living. Many cartoneros live in outlying shantytowns. Cartoneros - individuals, families, and cooperatives-proliferated and by 2008 recycled an estimated $90 \%$ of the recycled waste in Buenos Aires (p. 48). ${ }^{5}$ WFL project leaders researched the population of the Buenos Aires greater metropolitan area (13 million), its garbage output (4500 tons/day), and the social context surrounding waste collection: that a formal, functional recycling program was not yet in place; that a government agency had sought to legitimize cartoneros who register with the agency by providing "credentials, gloves, tunics, [and] vaccinations;" and that the primary garbage collector is a "municipal and regional government amalgam with private affiliations" with ambiguous recycling motivations: some said they facilitate recycling and others said that recycling cuts into their profits since they are paid by the ton (p. 48). ${ }^{5}$ WFL project leaders also discovered that 2005 legislation mandated reductions in garbage going to landfills of "50 percent by 2012 and 75 percent by 2017 using 2004 levels as benchmarks" (p. 48). ${ }^{5}$ As WFL project leaders spoke over a period of several months with multiple local individuals and groups about waste collection and disposal, issues of corruption, organized crime, and conflicts of interest surfaced, which were difficult to completely negate or corroborate.

As WFL project leaders researched the socio-economic context, key interested parties in recycling emerged, and to map these, they used a rainbow diagram (drawing from the social analysis systems model of ${ }^{37}$ ). In Figure 1, we see how WFL mapped the various actors according to who has influence (most, moderate, and least) and who could be (most, moderately, or least) affected by the WFL project (p. 52). ${ }^{5}$ 


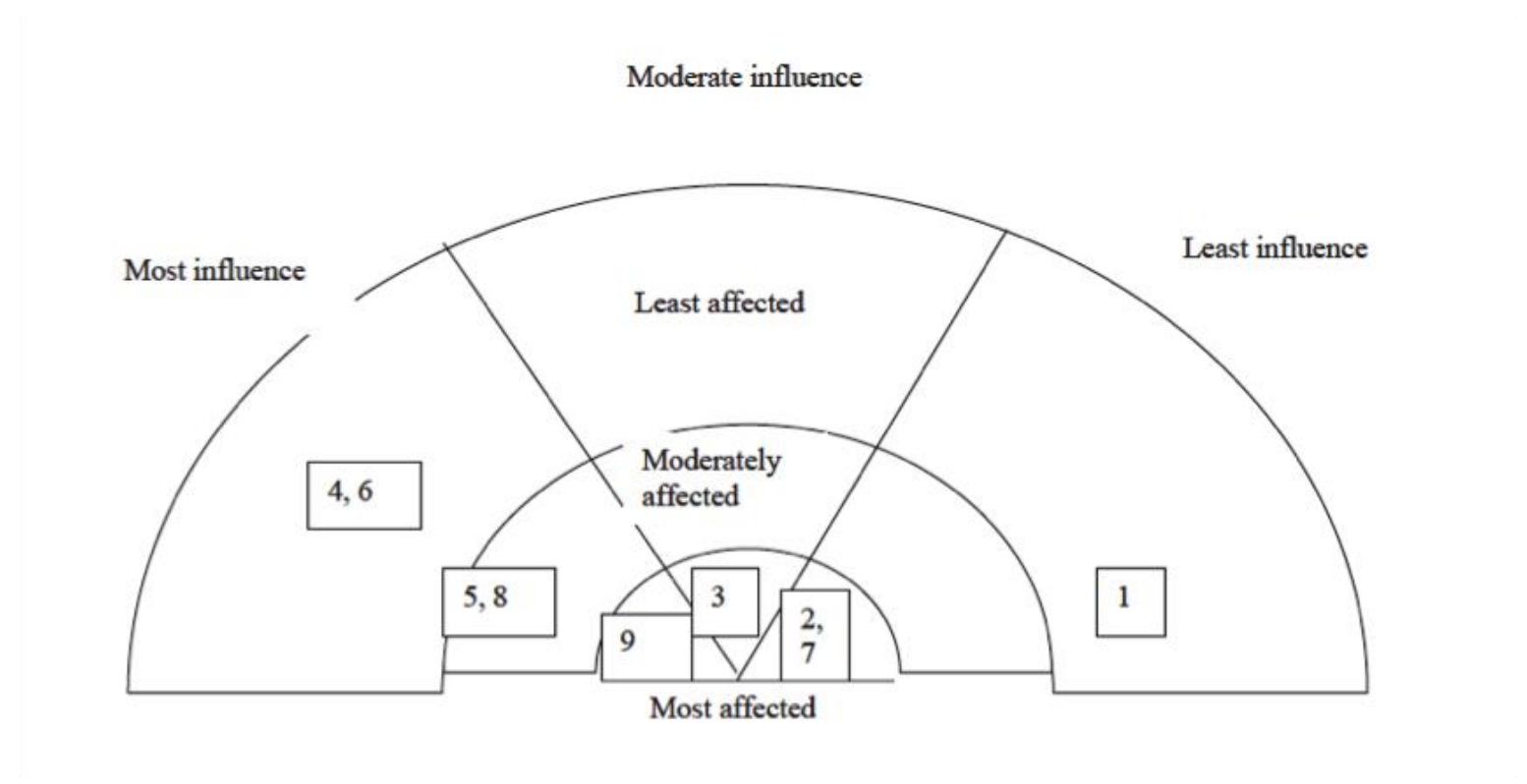

FIGURE 1

\section{RAINBOW DIAGRAM OF KEY ACTORS IN WFL PROJECT IN ARGENTINA (P. 52). ${ }^{5}$}

FIGURE 1: 1. STREET CARTONEROS, 2. SOCIAL FACTORY, 3. GREEN POINT COOPERATIVES, 4. GREENPEACE ACTIVISTS, 5. CEAMSE LANDFILL OPERATORS, 6. DGPRU (GOVERNMENT URBAN RECYCLING PROGRAM), 7. CARTONERO COOPERATIVES, 8. MANAGERS/OWNERS OF CHINESE SORTING UNITS/RECYCLING FACTORIES, 9. UNIVERSITY OF BUENOS AIRES (p. 52). ${ }^{5}$

The rainbow diagram - and more importantly, the time and thought dedicated to mapping political agents and opportunities for mobilizing power-is a critical and often missing component in HE/LTS initiatives. Among other benefits, the rainbow diagram is a map of power relations that allows HE/LTS students and faculty as well as community members - in this case, especially cartoneros - to understand which actors play key potential roles of influence and which actors may be most affected by community member's (and others') decisions. In that sense, the power mapping process yields insight into the critical barriers and opportunities for mobilizing power in a given HE/LTS context.

When mapping power relations in HE/LTS work, it is also important to recognize both fairly obvious and subtle forms of power. In some cases, power may be shared in clearly unequal ways according to gender, ethnicity/race, and social class, etc. For instance, in their playground design, LSU students realized that their taken-for-granted assumptions about the availability of resources at K-12 schools stemmed from social class privilege and lack of actual lived experiences at public schools, which is in turn linked to racial/ethnic privilege. But more nuanced power inequalities may also emerge. To unveil power nuances, students doing HE/LTS work need to understand the concept of unconscious bias. Such bias occurs when we remain unaware of and thus do not acknowledge inequitable distributions of privilege (a form of power) along multiple social identities - ethnicity/race, class, gender, disability status, sexual orientation, and others. As research on privilege has pointed out, for those with more privilege, there is comfort in maintaining unconscious bias:

The ease of not being aware of privilege is an aspect of privilege itself, what some call "the luxury of obliviousness" (or, in philosophy, "epistemic privilege"). Awareness requires effort and commitment. Being able to 
command the attention of lower-status individuals without having to give it in return is a key aspect of privilege. African Americans, for example, have to pay close attention to whites and white culture and get to know them well enough to avoid displeasing them, since whites control jobs, schools, government, the police, and most other resources and sources of power. White privilege gives whites little reason to pay attention to African Americans or to how white privilege affects them. In other words, as James Baldwin put it, 'To be white in America means not having to think about it' (p. 22). ${ }^{38}$

To promote HE/LTS student awareness of their own privilege and their relationships to existing power structures due to their social location, we have used two activities: the Privilege Walk and Privilege By Numbers Activities. Both activities foster awareness of the political agency of others but also of students' own agency in relation to privilege structures.

After having students read an overview of privilege (e.g., chapters in $^{38}$ ), they engage what can be a difficult topic to explore. The Privilege Walk was originally structured to promote awareness of race and gender privileges ${ }^{39,40}$ but has since been expanded to include additional forms of privilege such as social class, sexual orientation, ability, etc. We have found that engineering students are more receptive to engage in SJ if they become aware of their own privileges by virtue of their positioning in different sociological categories (gender, class, race/ethnicity, etc.) and their relationship to engineering. The Privilege Walk helps them see for themselves that they are not all equal, nor have equal opportunities, that their achievements in life have not been a product exclusively of their individual efforts, and that once they recognize their privileged position, instead of feeling guilty, they can put it to good use towards SJ causes. On the very first day of our Engineering and Social Justice class, we invite students outside to a open space where they form a line, shoulder to shoulder; we read about 50 questions, one by one, and, after each question, they take a step forward for an affirmative answer, or take a step backwards for a negative one. If students think their answers are neither "generally yes" nor "generally no," they can stay in place. Examples of questions appear below:

- I can open engineering magazines and see people of my skin color WIDELY represented (not just in the sections or articles dealing with diversity) and usually in positions of power or influence.

- I can be sure that children in the community where I live will be given curricular materials in engineering and technology subjects that testify to contributions made by people of my gender.

- At least one of my parents is a professional and has held steady jobs for most of his/her professional life.

- I can speak in public to a powerful group of engineers about controversial issues (and even get emotional and have my voice break) without putting my gender on trial.

- I can be almost certain that if I ask to talk to "a person in charge" (e.g., dean, provost, president) at my school or during my next visit to another engineering school, I will be facing a person of my ethnicity.

We have also used a modified version of the Privilege Beads Activity ${ }^{41}$ which we call Privilege by Numbers. The activity has three primary phases: setting the stage, counting privileges, and debriefing. A series of statements sets the stage so students know the activity may be challenging yet will occur in a safe context. In our version, students count and later report their privileges individually and anonymously. Each student first reads a posted list of 
eight privilege statements on cisgender, gender, nationality, religion, class, race, ability, and sexuality (64 statements total). The eight lists are posted around the room, and students can visit the lists in any order; after counting their privileges, a master sheet circulates, on which they can circle the number of privileges they had between zero and 64. That sheet is then placed on the board for discussion, and a specific sequence of debrief questions is followed. ${ }^{42}$ Among other realizations, students see how privileges are often both unearned and unequally distributed, so the activity fosters awareness of how invisible privileges are until they are discussed explicitly.

To deepen HE/LTS student understanding of how power relations can be mapped effectively or ineffectively, and the resulting consequences, we recommend the Bhutan case noted above, ${ }^{31}$ the WFL case, ${ }^{26}$ the case of the Transmilenio transportation system in Bogota, Colombia, ${ }^{38}$ and the growing library of case studies in the Synthesis Lectures on Engineers, Technology and Society edited by Caroline Baillie. ${ }^{39}$ Collectively, awareness of power and privilege issues inevitably raise questions as to whether and how students working on HE/LTS projects should render more visible the perspectives of those who are in positions of power (dis)advantage.

\section{Increasing opportunities and resources}

In HE/LTS contexts, one of the primary means by which human capabilities (discussed below) are augmented is by increasing opportunities and resources. Distinctions between opportunities and resources become clearer via example. If a community of individuals who are quadriplegic and those who work with them seek better bicycle designs, such bicycles can provide opportunities for those people to access roads for recreation, exercise, health, and a sense of overcoming any fears some may have about cycling. However, those opportunities are only accessible if the cyclists can acquire the necessary resources (bicycles and related equipment such as helmets). Thus, HE/LTS initiatives should measure their success in part by the degree to which they increase opportunities and access to those via augmented resources.

A capstone design team in our university re-designed the braking system and seat for mountain bikes to be used by individuals who are quadriplegic. As most such individuals have insufficient gripping power to activate a typical bike brake lever, the team had to redesign the way the rider activates the brakes by adding a pedal that can be activated with the bottom of the hand palm and a strap system to keep the rider's hands in place (see Figure 2). Also, most individuals who are quadriplegic have considerable difficulties in adjusting their torso position on the bike to compensate for imbalances by shifting their center of gravity (forward, backwards, or sideways), as non-disabled riders can do by moving their hips and legs. Hence the team redesigned the bike seat to compensate for this difficulty (see Figure 3). Through both redesigns, the team increased both resources - an improved mountain bike - and for people who are quadriplegic, opportunities for recreation, exercise, and access to public lands while mountain biking. Of course, the use of this resource and opportunities would be difficult without other resources and opportunities made available to individuals who are quadriplegic by other actors in the socio-technical system that supports mountain biking for persons with disabilities. For instance, the ski resort has to make available a chairlift, and additional staff, that accommodates the bikes and takes the bikers to the top of the mountain; the city has to make available wheelchair-accessible ramps and sidewalks so the bikers can get from their vehicles to the shop where they rent the bikes. In all of these integral components of the socio-technical system, engineers play key roles if they recognize their contributions to enhancing opportunities and resources. HE/LTS project designers need to ask, "How does our design increase opportunities and resources for those 
who will use and be affected by that design?," as inquiries into that question can lead to more effective sociotechnical designs.

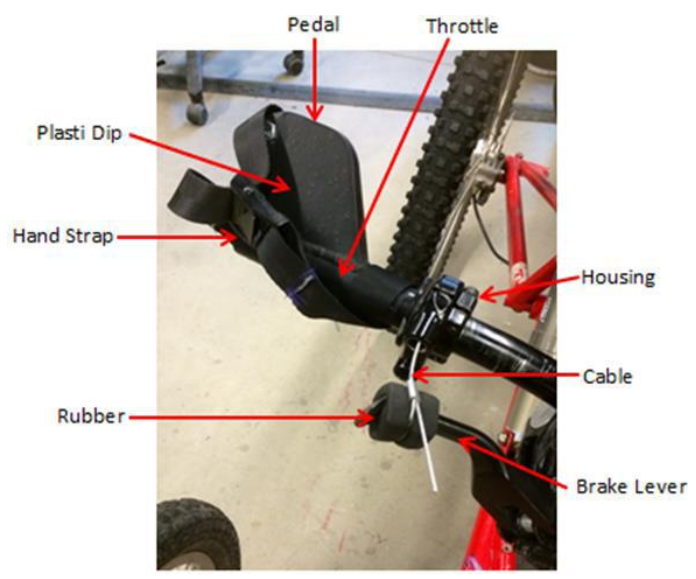

FIGURE 2

BIKE BRAKE CONFIGURATION

FIGURE 2: PHOTO OF THE 2014 COLORADO SCHOOL OF MINES SENIOR DESIGN TEAM "CSM FOURCROSS " BIKE BRAKE CONFIGURATION WITH REDESIGNED HAND STRAP, HAND PEDAL, THROTTLE, HOUSING AND BRAKE LEVER, WHICH ALLOWS A RIDER WITH LITTLE OR NO GRIP POWER TO ACTIVATE BRAKES.

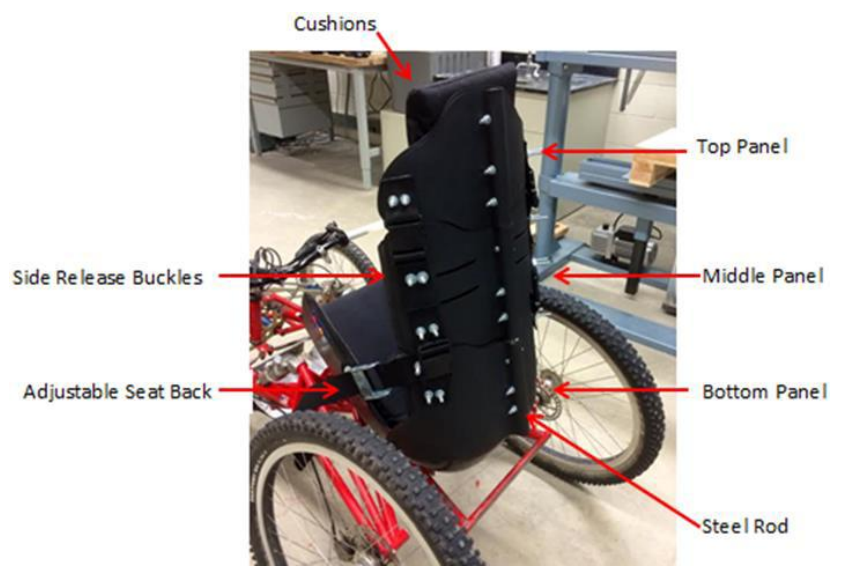

FIGURE 3

BIKE SEAT CONFIGURATION

FIGURE 3: PHOTO OF THE 2014 COLORADO SCHOOL OF MINES SENIOR DESIGN TEAM "CSM FOURCROSS "' BIKE SEAT CONFIGURATION WITH REDESIGNED PANELS, STEEL ROD, BUCKLES, AND CUSHIONS FOR A STABLE POSITIONING OF A RIDER'S TORSO.

\section{E. Reducing imposed risks and harms}

In HE/LTS contexts, solutions should reduce imposed risks and harms. Here risks and harms do not refer to those knowingly assumed by people but those risks and harms unwittingly imposed on users of a product or service.

Beyond the physical barrier imposed by inaccessible roads, people with physical disabilities, and especially those who are quadriplegic, can also face other potential risks and harms in their quest to experience mountain biking. For instance, since individuals who are quadriplegic often lack sufficient grip power, standard brake systems impose serious risks 
and harms to them unless they are redesigned as described above. At the mountain, engineers and surveyors need to carefully think about the layout of bike trails for individuals who are quadriplegic, as such trails need to be wider, have gentler slopes, and be mostly obstacle free, otherwise disabled riders can incur serious risks and harms. Although the Americans with Disabilities Act applies to new developments of relatively flat spaces in Federal lands (such as camping sites, or parking spaces), it does not apply to mountain bike trails. And the International Mountain Bike Association only provides construction guidelines for trails used by non-disabled riders. Hence, not bounded by law nor construction guidelines, engineers designing trails for handicapped riders can reduce risks and harms by developing empathy with these riders.

To reduce imposed risks and harms, empathy for users is particularly important, particularly when designers do not share the same lived experiences as users. For instance, when serving as social context consultant for a capstone design project involving wheelchair users, one of our colleagues asked students to spend an entire school day on campus moving from class to class in a wheelchair so they can feel all the obstacles, inconveniences, stares, etc. that wheelchair-bound students experience. Such lived experiences not only promote empathy but inform the edge sensor system the team designed, which is able to detect a threeinch drop-off in a variety of light levels and ground compositions (see Figure 4).

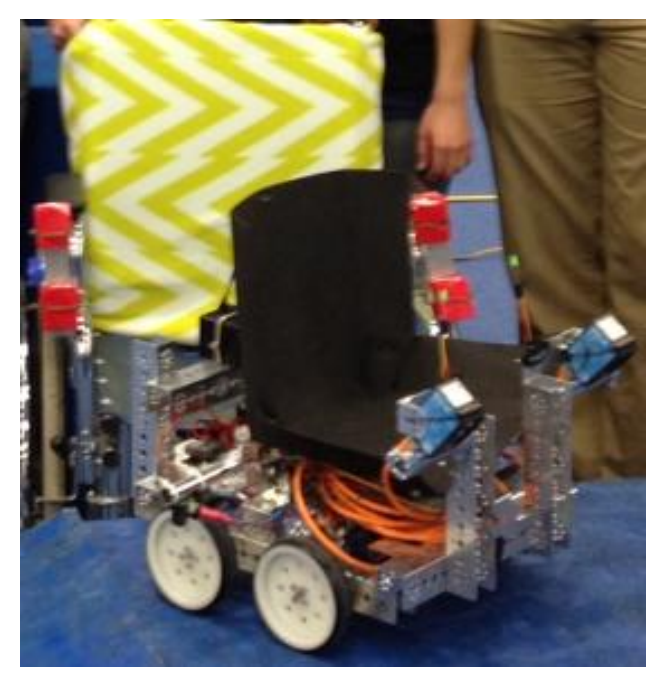

FIGURE 4

EDGE SENSOR SYSTEM

FIGURE 4: MINIATURE VERSION DESIGNED BY CSM SENIOR DESIGN TEAM "COLORADO ADVANTEDGE;" THIS EDGE SENSOR SYSTEM IS CAPABLE OF DETECTING A THREE-INCH DROPOFF IN A VARIETY OF LIGHT LEVELS AND GROUND COMPOSITIONS.

\section{E.1 Project and classroom tools}

One useful vehicle for engendering empathy is method cards, designed to unveil "diverse ways that design teams can understand the people they are designing for" and "to be used by researchers, designers, and engineers to evaluate and select the empathic research methods that best inform specific design initiatives". ${ }^{40}$ The 51 cards (now available in an App) are split into four categories-Learn, Look, Ask, Try-and accentuate how particular methods were used in actual design contexts. For instance, the Look (observe) card "A Day in the Life" asks designers to "catalogue the activities and contexts that users experience throughout 
an entire day". ${ }^{40}$ This method helps designers experience and thus build some empathy for the kinds of risks and harms users could encounter. Such activities operationalize research that encourages human-centered designers to engage in perspective taking and imagining oneself in others' lived experiences. ${ }^{41}$

\section{F. Enhancing human capabilities}

In an earlier SJ definition we used when teaching Engineering and Social Justice, a missing dimension became apparent when students would ask, "What are the increases in opportunities and resources and the reduction of risks and harms for?" To address that question, we have turned to SJ research on human capabilities ${ }^{22,26,27}$. The five SJ criteria described above (A-E) constitute means to an end, or rather, a series of ends: enhancing a host of human capabilities. Here we provide brief context on the capability approach, briefly define the 10 capabilities, and show how those apply to HE/LTS work. Nussbaum (a philosopher) and Sen (an economist) have argued that development should be for the enhancement of human capabilities, and we argue that enhancing human capabilities serves as an end to strive for when designing for social justice.

Although both Nussbaum and $\operatorname{Sen}^{42-43}$ have laid the foundation for the Capability Approach, our work derives most prominently from Nussbaum; we also draw extensively here from our previous research. ${ }^{23}$ Readers interested in other SJ frameworks can consult, for example, Riley ${ }^{15}$ or Passino ${ }^{44}$. Nussbaum's 10 human capabilities, as alluded to above, establish a key missing dimension in the definition of SJ and help us make sense of what HE/LTS initiatives can aspire to achieve. Useful in evaluating progress in community development projects, Nussbaum's 10 human capabilities emerge from asking SJ questions and serve "as a benchmark for a minimally decent human life" (p. 22). ${ }^{27}$ Research applying the capability approach to technological design emphasizes that

According to the capability approach, a key evaluative space in these areas [justice, equality, well-being, and development] is not income, not resources, not primary goods, not utility (i.e., happiness or the sum of pains and pleasures) or preference satisfaction. Its proponents argue that the focus should rather be on human capabilities. Capabilities are often described as what people are effectively able to do and be or the positive freedoms that people have to enjoy valuable 'beings and doings.' (p. 4). ${ }^{50}$

Nussbaum's positive freedoms are 10 human capabilities that include:

1) life (of a normal length)

2) bodily health

3) bodily integrity (freedom from assault and the ability to move about freely, etc.)

4) senses, imagination, and thought (which are critical to being fully human)

5) emotions (love, grief, longing, gratitude, and more)

6) practical reason (for critical thinking, freedom of conscience, etc.)

7) affiliation (including protecting institutions that advance compassion and ensuring the social preconditions for self-respect and non-humiliation regardless of sex, ethnicity, sexual orientation, etc.)

8) other species (how we manifest respect for plants, animals, and nature in general),

9) play (recreation, laughter), and

10) control over one's political and material environment. 
Research on the capability approach accentuates the importance of protecting social institutions and preconditions necessary for promoting and enhancing each capability or multiple ones. ${ }^{27-28}$

If human capabilities are a crucial end goal, the effectiveness of HE/LTS initiatives can be measured in part by how well such initiatives enhance human capabilities. That measurement may be indirect or direct. For instance, life of a normal length and bodily health align indirectly with engineers' ethical mandate to "hold paramount the safety, health, and welfare of the public." ${ }^{51}$ However, the capabilities can also apply more directly, depending on community desires and aspirations. For instance, if an elementary school community desires a playground that expressly accentuates the goal of affiliation (ensuring playground equipment that fosters self-respect and non-humiliation) and the goal of interactive play (among individuals of various physical abilities), the ways in which the final solution promotes such capabilities can be assessed.

\section{F.1 Project and classroom tools}

Interest has surged recently in the intersection between the capability approach and technological design. ${ }^{52,53,54,55}$ In this research, effective technology is positioned as that which is purposefully designed to promote human capabilities. The capability approach is a core criterion in our SJ definition, and many of the other criteria exist so they can facilitate the crucial end of enhancing human capabilities. To put these ideas into practice, we have asked students to use the capabilities in an evaluation matrix (Table I). The matrix can be used when evaluating, for instance, the Bhutan and WFL design case studies. After analyzing others' designs, students can do the same for their own design alternatives.

\section{TABLE I}

DESIGN EVALUATION MATRIX ON HUMAN CAPABILITIES

\begin{tabular}{|l|l|l|l|l|l|l|l|l|l|l|l|}
\hline & Life & $\begin{array}{l}\text { Bodily } \\
\text { health }\end{array}$ & $\begin{array}{l}\text { Bodily } \\
\text { inte- } \\
\text { grity }\end{array}$ & $\begin{array}{l}\text { Senses, } \\
\text { imagina- } \\
\text { tion, } \\
\text { thought }\end{array}$ & Emotions & $\begin{array}{l}\text { Practical } \\
\text { Reason }\end{array}$ & $\begin{array}{l}\text { Affilia- } \\
\text { tion }\end{array}$ & $\begin{array}{l}\text { Other } \\
\text { species }\end{array}$ & $\begin{array}{l}\text { Play } \\
\text { over } \\
\text { environ- } \\
\text { ment }\end{array}$ & TOTAL \\
\hline DesignA & & & & & & & & & & & \\
\hline Design B & & & & & & & & & & & \\
\hline Design C & & & & & & & & & & & \\
\hline
\end{tabular}

Weigh factor $(1=$ less important to $5=$ most important $)$

With historical case studies, students can evaluate how the actual design affected users' human capabilities over the long run. With contemporary cases and their own design alternatives, importance can be estimated in terms of the degree to which designers made specific modifications to address a given relevant capability. In using the design evaluation matrix, it is expected that different engineers will weigh these 10 capabilities differently, and it is precisely this diversity of perspectives that offers a rich opportunity for negotiation of what matters most, to not only the engineering designers but also the community and other stakeholders.

\section{SJ Criteria Combined}

In relationship to engineering, we have defined $\mathrm{SJ}$ as engineering practices that strive to enhance human capabilities (goal) through an equitable distribution of opportunities and resources while reducing imposed risks and harms (means) among agentic citizens of a specific community ${ }^{24,25,26,27}$. Hence, the criteria give us both a specific set of goals to strive 
for in our design work - enhancing human capabilities - as well as provide tools by which to achieve those ends. That is, in HE/LTS work, we listen contextually, identify structural conditions, acknowledge political agency and mobilize power so that we can learn how to better enhance human capabilities. Similarly, we have the enhancement of human capabilities foremost in mind when we inquire into ways to increase opportunities and resources as well as decrease imposed risks and harms. How do we know that our designs are successful? Answering that question is not just a matter of achieving client satisfaction, addressing user preferences, or winning design competitions, but of inquiring into whether our designs address broader issues of social justice by attempting to enhance human capabilities. Our definition above refers to agentic citizens of a specific community to underscore the importance of not just community involvement (a minimal expectation), but community agency in shaping the outcome-including how it is assessed for effectiveness - of any HE/LTS project. The six criteria should at every available juncture promote community agency, the community's ability to achieve self-determination. ${ }^{15}$

\section{BENEFITS OF INTEGRATING SJ}

In HE/LTS work, the number and complexity of constraints is significant given the openended nature of projects and potential variables such as community ownership, intercultural awareness, and more. Although adding the SJ criteria only makes something already complex even more laden with complexity, it focuses our attention on a goal of paramount importance: enhancing human capabilities. Beyond highlighting the value of human capabilities, the criteria provide several additional distinct benefits in conducting HE/LTS work.

1) The SJ criteria act as heuristics, providing a mechanism for structuring all phases of HE/LTS projects, from project definition to formative and summative reflection. As noted in community engagement research, ${ }^{56}$ Kolb's research suggests that the learning cycle occurs when lived experiences lead to concepts that in turn guide students in future learning experiences. ${ }^{57}$ In HE/LTS contexts, that cycle, according to Jacoby, becomes operationalized via recurring opportunities and challenges to engage in and reflect on new experiences. ${ }^{58}$ Although critical reflection is an essential component of HE/LTS projects, 56, 58, 59, 60 such reflection needs some structure. The SJ criteria raise questions that can facilitate critical reflection, acting as structured yet adaptable heuristics, as noted in Table II. 


\section{TABLE II}

\section{SOCIAL JUSTICE CRITERIA AS HEURISTICS FOR CRITICAL REFLECTION}

\begin{tabular}{|l|l|}
\hline \multicolumn{1}{|c|}{ SJ Criterion } & \multicolumn{1}{c|}{ Questions for Critical Reflection } \\
\hline $\begin{array}{l}\text { A. Listening } \\
\text { contextually }\end{array}$ & $\begin{array}{l}\text { How has listening been integrated into all project phases, from } \\
\text { problem definition to eventual solution? What specific efforts have } \\
\text { we made to transcend basic listening and listen contextually? How } \\
\text { have we situated information such as cost, weight, technical specs, } \\
\text { desirable functions, and timeline within the LKD context of the } \\
\text { community and users? }\end{array}$ \\
\hline $\begin{array}{l}\text { B. Identifying } \\
\text { structural } \\
\text { conditions }\end{array}$ & $\begin{array}{l}\text { Throughout the project process, what specific structural conditions } \\
\text { have we identified that (may) enable, constrain, or otherwise affect } \\
\text { community aspirations? Structural conditions might relate to, for } \\
\text { instance, socioeconomics, family, law, religion, or education. How } \\
\text { have we tried to be aware of our own potential blind spots in } \\
\text { identifying structural conditions, perhaps related to gender, social } \\
\text { class, ethnicity, sexual orientation, age, and ability? How does this } \\
\text { awareness impact our design? }\end{array}$ \\
\hline $\begin{array}{l}\text { C. Acknowledging } \\
\text { and mobilizing } \\
\text { power }\end{array}$ & $\begin{array}{l}\text { What lessons learned emerged from mapping political agents and } \\
\text { opportunities for mobilizing power in terms of a rainbow diagram? } \\
\text { How did the diagram morph as the project evolved? What steps } \\
\text { have we taken in our attempt to surmount unconscious bias? } \\
\text { Should HE/LTS engineers help give voice to the perspectives of } \\
\text { those who are at power disadvantages? }\end{array}$ \\
\hline $\begin{array}{l}\text { F. } \text { Reducing } \\
\text { imposed risks and } \\
\text { harms }\end{array}$ & $\begin{array}{l}\text { In what ways does our design solution reduce imposed risks and } \\
\text { harms? What specific risks and harms does our design reduce, } \\
\text { eliminate, or mitigate? }\end{array}$ \\
\hline $\begin{array}{l}\text { How Increasing } \\
\text { opportunities and } \\
\text { those who will use and be affected by that design? What specific } \\
\text { opportunities or resources does our design increase, promote, or } \\
\text { defend? }\end{array}$ & $\begin{array}{l}\text { In what specific ways does our design enhance human } \\
\text { capabilities? How has our focus on such capabilities resulted in a } \\
\text { better project or design outcome? }\end{array}$ \\
\hline
\end{tabular}

These heuristics can be adapted to benefit engineering students and engineers at multiple HE/LTS phases: pre-, mid-, and post-project. If considered only in the later stages of a project, the heuristics will likely be less useful. The cost of undoing or correcting mistakes increases significantly as the project evolves; earlier is not only better but cheaper. As we noted above, the criteria inform and expand the problem definition phase in HE/LTS initiatives. In addition to providing structure throughout the reflection process, the SJ heuristics attune students to often-neglected issues in problem definition, project development and implementation, as well as post-project monitoring and evaluation of lessons-learned. 
2) The SJ criteria build from a clear definition of SJ. We concur with Nussbaum when she writes, "One cannot say, 'I'm for justice, but any conception of justice anyone comes up with is all right with me.' " (p. 47-48). ${ }^{61}$ A clear SJ definition and resulting criteria have two specific benefits: a) as noted above, the criteria can be operationalized and judiciously applied to increase the probability that SJ is enacted in multiple phases of HE/LTS work. b) The criteria provide ways of answering crucial and often neglected questions. We applaud those who have accentuated the potential of HE/LTS work to promote engaged student learning of engineering as well as to advance the common good (e.g. ${ }^{56}$ ). That framing is important — but incomplete. What lies behind the learning of engineering and advancing the common good? How do we engage those students who ask, "What and who is engineering for? What and who is community engagement for?" The SJ definition and criteria add a missing dimension to a prominent definition of community engagement:

Community engagement (CE) in engineering education is a form of active, experiential learning where students, instructors, and the community partners work collaboratively on projects that benefit a real community need and provide a rich learning experience for all participants. The CE must be properly planned, implemented, and assessed with expected outcomes, educational and others, in mind. Critical reflection is part of this assessment effort. (p. 362) $)^{56}$

While useful, this CE definition does not raise the question of what motivations underlie activities in community engagement, or for that matter, what lies behind the desire to help and to learn. Also, the CE definition leads students to ask in what ways might the project benefit a real community need? The SJ definition and criteria provide students with a flexible set of tools to obtain richer answers to such questions - and where answering such questions will lead.

3) The SJ definition and criteria provide a mechanism to enhance engineering ethics. For many years, Herkert has challenged scholars and practitioners in engineering ethics to move from microethics to macroethics. ${ }^{62}$ Microethical issues include, for instance, conflicts of interest, allocation of credit, authorship practices, and research misconduct. While all those are important, Herkert challenges us to also focus on macroethical issues, ones of broader social significance and potential impact, such as externalizing environmental costs from industry to the public, systemic social inequities, and other large-scale societal impacts. Fortunately, more recent engineering ethics textbooks have acknowledged the important role of macroethics. ${ }^{17,}{ }^{63}$ By integrating the SJ criteria into HE/LTS initiatives, we foreground macroethical issues, making an important step toward rising to Herkert's challenge.

4) The SJ criteria facilitate a needed transformation from weak to robust conceptualizations of sustainability. Many have noted that in the trifecta common to robust definitions of sustainability_Profit, Planet, and People, ${ }^{10}$ or Economy, Environment, Equity ${ }^{64}$ — varying degrees of attention are paid. Generally, one gets ample attention (profit, economy), another less (planet, environment), and the third is ignored or relatively neglected (people, equity). ${ }^{65}$ The SJ criteria help engineers foreground a more robust version of sustainability by placing renewed emphasis on people and equity. Although the challenges of measuring or quantifying people and equity issues remain, we will only improve our attempts to educate engineers if we present these as important challenges. 
5) For many years, the two authors have read papers by and sat in conferences with HE/LTS faculty and realized that in published work and in conference presentations, there is a 600pound gorilla in HE/LTS work that no one wants to fully acknowledge: power relations. But we must. We ignore power relations at our - and our students'-peril. The SJ criteria provide a tool, the rainbow diagram, by which to map how such relations impact HE/LTS projects. Now that the gorilla has been acknowledged, we can discuss ways to mobilize power to "benefit a real community need" (p. 362). ${ }^{56}$

6) For students who despise government-mandated redistribution (e.g., taxes, regulations, equal opportunity policies), they can become agents of SJ through their designs. Most of our students come from politically conservative, pro-industry backgrounds, yet they find it liberating to be able to apply these criteria to their projects, feel that they are doing the right thing, while not having to rely on the government to tell them what to do. Reflecting at the end of the Engineering and Social Justice course in which we apply the criteria to many engineering projects, one of our most conservative students contrasted his views before and after taking the class:

I had the idea that implementing social justice was at best going to be a zero sum outcome and at worst a net negative. Social justice meant taking away from someone who earned something and giving it to someone who didn't earn something. And there is a thought, although it might not be spoken often, that by a redistribution of wealth and opportunity, it will be wasted because the intended target of the redistribution has never accomplished anything to begin with.... I have friends and family that will claim that until their deathbed.... One of my initial perceptions of engineering and social justice was this idea that good engineering and social justice were incompatible. This is because using the previously described idea of social justice, the inefficiency of social justice projects and the efficiency of good engineering just could not coexist. This perception could be fit into any of the five engineering mindsets [explored at depth in class via ${ }^{21}$ ], but the most important aspect of the perception is that it is completely false. Not only can good engineering and social justice exist simultaneously, but it can be argued that the very definition of good engineering is taking into account social justice.

7) SJ criteria could assist in fostering integration of diverse populations in engineering education and practice. Community engagement has been described as a vehicle for inclusiveness. ${ }^{56}$ Our experiences with students who have lost the romance or fascination of engineering (e.g., many seniors) suggest that thoughtfully integrating SJ criteria into design and other technology education sparks student interest, motivation, and engagement. Although we have not yet researched the degree to which SJ dimensions could serve as a vehicle for recruitment and retention of underrepresented populations in engineering, our anecdotal experiences over the past 10 years show great promise in this area. Integrating SJ in engineering education might be a vehicle to attract one of the most ignored and invisible underrepresented demographic groups: low-income students. Preliminary research shows that engineering students from low-income backgrounds might actually be the most appropriate and effective innovators to translate engineering for community development into SJ. ${ }^{66}$ 


\section{LIMITATIONS OF SOCIAL JUSTICE CRITERIA}

Although it is now obvious, it merits reiterating that engaging the six criteria above in HE/LTS initiatives introduces additional layers of complexity. If students' training has conditioned them to reduce, simplify, and solve closed-ended problems, they may meet that complexity with resistance, especially at first. Even when the criteria are effectively integrated into HE/LTS work, we still have to recognize that we bring (consciously or otherwise) to the process an interpretive framework or perspective that can shift what we see, do not see, and how we see it. As the WFL project organizers acknowledged, "even 'hearing' [diverse community perspectives] may not be enough because ... our interpretations of what we hear will always be translations from the original, molded by our habits of thoughts, and that in those translations, something may be lost or ignored or suppressed that may need to be recaptured" (p. 9). ${ }^{5}$ Research has indicated that the interpretive frameworks we bring even to issues on which scientists have reached a consensus, such as aspects of climate change and the safety of nuclear waste disposal, shape how we interpret or filter scientific information. ${ }^{67}$ If those researchers' findings (in ${ }^{67}$ ) are valid, it is even more likely that we can filter more inherently ambiguous information, such as that which emanates from HE/LTS community engagement processes. Yet ultimately, the benefits of acknowledging the complexity inherent in HE/LTS projects outweighs the disadvantages, largely because doing otherwise shortchanges our engineering students and engineers in learning about the fullness, wonder, and challenges of engineering design.

For some faculty, venturing into SJ is unfamiliar terrain. In our interviews with faculty, they told us that SJ may seem quite foreign to some HE/LTS instructors, and far outside the technical domains in which they may feel most comfortable. At the same time, most faculty in HE/LTS work ventured into unfamiliar terrain at some point in their careers, so the precedent exists for "diving in" to uncharted waters. That raises the question of motivation and incentives of integrating SJ dimensions, for faculty and students. From our experiences and those we interviewed, engaging the SJ dimensions of HE/LTS work renders visible once-hidden or subtle aspects of HE/LTS, and is a catalyst for student engagementand better designs, models, etc.; rather than see SJ dimensions as a political intrusion in their designs and service work, students have reported a heightened sense of meaning and purpose. The quote above by one of our most conservative students is not unique. We have seen remarkable transformations in students from the entire political, religious, social and cultural spectra. In light of their current apathy towards politics and their skepticism that the corporate sector can be an advocate for SJ, students find it empowering to know that they can integrate SJ into the design and development of their projects and become agents for positive social change.

Still, faculty incentives for diving in SJ waters may be compromised by our own realistic time constraints and the various reward systems within our institutional contexts. Despite these challenges, we have chosen to dive in anyway; if that is not possible for others, faculty can wade in gradually. For us, the long-term rewards in terms of bringing engineering design and modeling alive in HE/LTS programs outweigh the costs. One method of alleviating initial faculty discomfort with the complexity of SJ dimensions is to deny any expertise and provide students tools - like the six criteria above - and encourage structured reflection and iterative team-learning. In our experience, students use such tools in ways that not only surprised us - they amazed us. Former students from our Engineering and Social Justice class have integrated SJ criteria in their Senior Design Projects and have won the "Overall Best Design" in our school's trade fair three semesters in a row, providing evidence for the assertion from the student above that "not only can good engineering and social 
justice exist simultaneously, but it can be argued that the very definition of good engineering is taking into account social justice."

One of our HE/LTS faculty interviewees noted that resistance to SJ dimensions stemmed from a misguided assumption: that technical content should drive HE/LTS courses, just as it does in the engineering science core (e.g., statics, dynamics, fluids, etc.). Yet emphasis on content misses important dimensions: How do we make assumptions in HE/LTS contexts? How do we frame problems? How do we teach different ways of knowing? How do we engage the community? By skipping over such messy, complex issues, we privilege technical ways of knowing and ignore important sociotechnical ways of knowing. The SJ criteria foreground such ways of knowing.

Another limitation is also an opportunity in disguise. Integrating SJ is bound to meet some faculty resistance. If SJ is going to have a foothold in HE/LTS curricula, it will need to link with politically powerful initiatives on campus, such as HE/LTS programs that have a positive, established reputation. Such connections will provide the clout needed to integrate SJ explicitly, as is done in the Ohio State University Humanitarian Engineering Program ${ }^{49}$ and elsewhere.

When considering SJ criteria integration in HE/LTS initiatives, we run into the reality that the engineering curriculum is already overflowing with courses, content, and concepts. If elaborated, each SJ criterion could constitute its own course, so scaling these can and should catalyze a rethinking of where the criteria fit best across the curriculum. For instance, in our own HE Program, listening contextually and other criteria are integrated into a course on Human-Centered Problem Definition, a pre-cursor to capstone design courses in our HE Program. Operationalizing these criteria within engineering curricula, given that they are initially foreign to many engineering faculty, will be challenging. At the same time, not taking on the challenge may result in HE/LTS projects that are artificially constrained, unrealistic, and oversimplified. We invite readers to join us in our journey toward understating how we can, given institutional and other constraints, solve these logistical challenges. Integrating SJ can also serve as a direct mechanism for meeting ABET accreditation challenges, such as Program Outcomes c (an ability to design a system, component, or process to meet desired needs within realistic constraints such as economic, environmental, social, political, ethical, health and safety, manufacturability, and sustainability), h (the broad education necessary to understand the impact of engineering solutions in a global, economic, environmental, and societal context), and $\mathrm{j}$ (a knowledge of contemporary issues). ${ }^{68}$

It is a fair critique of human capacities that their realization is not assured. Of course, this is true of the ends in any HE/LTS or SJ initiative, given the complex variables that can facilitate or hinder their realization. But human capacities focus community and engineers' efforts in work toward such ends, by breaking their realization into smaller, concrete steps. Also, critics can point out that much injustice can occur in the guise of risk reduction. While true, this should only further engineers' and communities' resolve to ensure that risk reduction is enacted in ways consistent with larger human capacity-building and SJ goals.

Some critics of the SJ criteria could see them as culturally situated, and not applicable to all cultural contexts. Yet in terms of the end goal, enhancing human capabilities, Nussbaum counters that:

1. Cultures borrow things from each other all the time (e.g., conceptions of rights, political constitutions, etc.). Gandhi appreciated the development of universal human rights even though he despised British political and economic imperialism. 
2. No culture is monolithic, so there will be groups within cultures that welcome the capabilities (those marginalized from power) and those who might resist it (those in power).

3. Human capabilities are abstract concepts that will take their own life and be implemented in different ways according to local customs, circumstances, etc.

4. Human capabilities are prescriptive (they direct us on what to look for) but are not directive (they do not direct communities how to go about achieving these). ${ }^{29}$

So after all, the cultural imperialism claim is questionable, and the cultural flexibility of how the criteria can be implemented becomes a benefit, not a limitation.

\section{FUTURE RESEARCH}

The road ahead calls for research and innovation on integrating SJ criteria to promote the long-term durability of HE/LTS programs: we need to continue to publish our carefully assessed pedagogical innovations that promote student transformation in how engineering can enhance human capacities; to show best practices in sustaining community partnerships, demonstrating the value of HE/LTS programs to engineering colleagues, making such programs visible in traditional academic rewards structures, engaging in interdisciplinary problem solving, and gaining funding for such programs. A foundation on these issues has been established in articles published in the 2013 IJSLE special issue on Opportunities and Barriers to Integrating Service Learning into Engineering Education, so the launch pad for future research is ready. That launch pad has also prepared a foundation for integrating SJ criteria in HE/LTS work, and all of us will learn more as we continue to assess how the SJ criteria reshape our students' thinking about engineering problem solving, design, and service. Our forthcoming book, Engineering Justice: Transforming Engineering Education and Practice, will feature assessment of SJ pedagogical innovations across three components of the engineering curriculum - engineering sciences, design, and liberal arts courses - and we look forward to continued experimentation with the social justice criteria as all of us collectively evolve our understanding of social justice dimensions in HE/LTS projects and programs and in exploring what it means to do engineering and to be an engineer.

\section{ACKNOWLEDGMENTS}

After more than 20 years (over 40 years combined) of lived experience as engineering educators, we have thousands of students to thank for helping us refine our still-evolving ideas on engineering and social justice. Particularly helpful have been over 20 combined years of working with engineering students in various engineering design contexts (as instructors, consultants or as a program director), as well as over a decade of combined research on engineering problem solving and engineering-SJ connections. We would also like to thank our editors at Wiley-IEEE Press for their insight and patience as we evolve our forthcoming book, Engineering Justice: Transforming Engineering Education and Practice. Our gratitude also goes to Dean Nieusma, whose remarkable knowledge of connections between engineering design and social justice has benefitted us immensely. Finally, we thank those students and instructors whose interview time has given us multiple insights into engineering-social justice linkages. 


\section{REFERENCES}

1. Laska, S. \& Morrow, B. H. Social Vulnerabilities and Hurricane Katrina: An Unnatural Disaster in New Orleans. Marine Technology Society Journal 40, 16-26 (2006).

2. Lima, M. Community at the Center of the Storm. Journal of Service-Learning in Higher Education 1, (2012).

3. Dukhan, N., Schumack, M. R., Daniels, J. J. \& Jenkins, M. G. Service Learning Case Study in Heat Transfer. international Journal for Service Learning in Engineering 2, 1-15 (2007).

4. Blue, E., Levine, M. P. \& Nieusma, D. Engineering and war: militarism, ethics, institutions, alternatives. (Morgan \& Claypool, 2014).

5. Baillie, C., Feinblatt, E., Thamae, T. \& Berrington, E. Needs and feasibility a guide for engineers in community projects : the case of Waste for Life. (Morgan \& Claypool Publishers, 2010).

6. Catalano, G., Baillie, C., Riley, D. M. \& Nieusma, D. Engineering, Peace, Justice and the Earth: Developing Course Modules. in Proceedings for the American Society for Engineering Education Annual Conference (2008).

7. Cech, E. Trained to Disengage? A Longitundinal Study of Social Consciousness and Public Engagement Among Engineering Students. in Proceedings for the American Society for Engineering Education Annual Conference (2010).

8. Riley, D. M. We've Been Framed! Ends, Means, and the Ethics of the Grand(iose) Challenges. in Proceedings for the American Society for Engineering Education Annual Conference (2011).

9. Nieusma, D. \& Tang, X. Teaching the Unbalanced Equation: Technical Opportunities and Social Barriers in the NAE Grand Challenges and Beyond. in Proceedings for the American Society for Engineering Education Annual Conference (2011).

10. Kamp, L. Engineering education in sustainable development at Delft University of Technology. Journal of Cleaner Production 14, 928-931 (2006).

11. Linhart, T. D. They Were So Alive!: The Spectacle Self and Youth Group Short-Term Mission Trips. Missiology 34, 451-462 (2006).

12. Schneider, J., Lucena, J. C. \& Leydens, J. A. Engineering to help: The value of critique in engineering service. IEEE Technology and Society 28, 42-48 (2009).

13. Lupton, R. D. Toxic Charity: How the Church Hurts Those They Help and How to Reverse It. (HarperCollins, 2011).

14. Leydens, J. A. \& Lucena, J. C. Listening as a missing dimension in engineering education: Implications for sustainable community development efforts. IEEE Transactions on Professional Communication 52, 359-376 (2009).

15. Lucena, J. C., Schneider, J. \& Leydens, J. A. Engineering and sustainable community development. (Morgan and Claypool, 2010).

16. Leydens, J. A., Lucena, J. C. \& Schneider, J. Are Engineering and Social Justice (In)commensurable? A Theoretical Exploration of Macro-Sociological Frameworks. International Journal of Engineering, Social Justice and Peace 1, 63-82 (2012).

17. Martin, M. W. \& Schinzinger, R. Introduction to engineering ethics. (McGraw-Hill/Higher Education, 2010).

18. Noble, D. America by design : science, technology, and the rise of corporate capitalism. (Knopf, 1977).

19. Wisnioski, M. H. Engineers for change: competing visions of technology in 1960s America. (MIT Press, 2012).

20. Layton, E. T. The revolt of the engineers: social responsibility and the American engineering profession. (Johns Hopkins Press, 1986).

21. Riley, D. Engineering and social justice. (Morgan \& Claypool, 2008).

22. Paterson, K. G. \& Fuchs, V. J. Development for the other 80\%: Engineering hope. Journal for Austraalasian Engineering Education 14, 1-12 (2008).

23. Leydens, J. A., Lucena, J. C. \& Nieusma, D. What is design for social justice? in ASEE Annual Conference and Exposition (ASEE, 2014).

24. Barry, B. Why social justice matters. (Polity, 2005). 
25. Capeheart, L. \& Milovanovic, D. Social Justice: Theories, Issues, and Movements. (Rutgers University Press, 2007).

26. Nussbaum, M. C. Women and Human Development: The Capabilities Approach. (Cambridge University Press, 2001).

27. Nussbaum, M. Human Rights and Human Capabilities. Harv. Hum. Rts. J. 20, 21-24 (2007).

28. Nussbaum, M. C. Frontiers of justice: disability, nationality, species membership. (The Belknap Press : Harvard University Press, 2006).

29. Nussbaum, M. C. Creating capabilities: the human development approach. (Belknap Press of Harvard University Press, 2011).

30. Downey, G. L. Are Engineers Losing Control of Technology?: From 'Problem Solving' to 'Problem Definition and Solution' in Engineering Education. Chemical Engineering Research and Design 83, 1-12 (2005).

31. Young, D. ., Mill, G. . \& Wall, R. Feasibility of renewable energy storage using hydrogen in remote communities in Bhutan. International Journal of Hydrogen Energy 32, 997-1009 (2007).

32. Baillie, C. Waste for life - Who we are. Waste for Life (2013). at $<$ http://wasteforlife.org/?page_id=2>

33. Downey, G. L. Risk in Culture: The American Conflict over Nuclear Power. Cultural Anthropology 1, 388-412 (1986).

34. Downey, G. L. Reproducing Cultural Identity in Negotiating Nuclear Power: The Union of Concerned Scientists and Emergency Core-Cooling,". Social Studies of Science, 18, 231-64 (1988).

35. Downey, G. L. Structure and Practice in the Cultural Identities of Scientists: Negotiating Nuclear Wastes in New Mexico. Anthropological Quarterly 61, 26-38 (1988).

36. Franklin, U. The real world of technology. (Anansi, 1999).

37. Chevalier, J. M. \& Buckles, D. Social analysis systems 2 (SAS2): a guide to collaborative inquiry and social engagement. (SAGE Publications, 2008).

38. Johnson, A. G. Privilege, power, and difference. (McGraw-Hill, 2006).

39. McIntosh, P. White privilege and male privilege: A personal account of coming to see correspondence through work in Women's Studies. (Wellesley College, 1988).

40. McIntosh, P. White privilege: Unpacking the invisible knapsack. Peace and Freedom 10-12 (1989).

41. National Association of College and University Residence Halls. Beads of Privilege Activity. NACURH (2014). at <http://www.nacurh.org/wordpress/wpcontent/uploads/2011/05/BeadsOfPrivilege_SamanthaHyland.pdf>

42. Allen, B. J. Privilege Beads Exercise. in CO-LEADS (2012).

43. Valderamma Pineda, A. F. in Engineering Education for Social Justice: Critical Explorations and Opportunities (ed. Lucena, J. C.) 203-226 (Springer, 2013).

44. Baillie, C. Synthesis Lectures on Engineers, Technology and Society. Morgan and Claypool Publishers (2014). at <http://www.morganclaypool.com/toc/ets/1/1>

45. IDEO. IDEO Method Cards. IDEO Method Cards (2014). at $<$ http://www.ideo.com/work/method-cards/>

46. Kouprie, M. \& Visser, F. S. A framework for empathy in design: stepping into and out of the user's life. Journal of Engineering Design 20, 437-448 (2009).

47. Sen, A. Development as freedom. (Knopf, 1999).

48. Sen, A. The idea of justice. (Belknap Press of Harvard University Press, 2009).

49. Passino, K. Table of Contents for Humanitarian Engineering: Creating Technologies that Help People. Table of Contents for Humanitarian Engineering: Creating Technologies that Help People. (2014). at <https://hebook.engineering.osu.edu/contents>

50. Oosterlaken, I. in The capability approach, technology and design 5, 3-26 (Springer, 2012).

51. in (National Society of Professional Engineers, 2007). at <http://www.nspe.org/ethics/eh1code.asp> 
52. Oosterlaken, I. Design for Development: A Capability Approach. Design Issues Design Issues 25, 91-102 (2009).

53. Nichols, C. \& Dong, A. in The capability approach, technology and design 5, 189-201 (Springer, 2012).

54. Murphy, C. \& Gardoni, P. in The capability approach, technology and design (eds. Oosterlaken, I. \& van den Hoven, J.) 5, 189-201 (Springer, 2012).

55. Frediani, A. A. \& Boano, C. in The capability approach, technology and design (eds. Oosterlaken, I. \& van den Hoven, J.) 5, 203-221 (Springer, 2012).

56. Swan, C., Paterson, K. \& Bielefeldt, A. R. in Cambridge Handbook of Engineering Education Research (eds. Johri, A. \& Olds, B.) 357-372 (Cambridge University Press, 2014).

57. Kolb, D. A. Experiential learning: experience as the source of learning and development. (Prentice-Hall, 1984).

58. Jacoby, B. Service-learning in higher education: concepts and practices. (Jossey-Bass, 1996).

59. Lima, M. \& Oakes, W. Service-Learning: Engineering In Your Community. (Great Lakes Press, 2006).

60. Lima, M. \& Oakes, W. C. Service-learning: engineering in your community. (2014).

61. Nussbaum, M. Capabilities as fundamental entitlements: Sen and social justice. Feminist Economics 9, 33-59 (2003).

62. Herkert, J. Ways of thinking about and teaching ethical problem solving: Microethics and macroethics in engineering. Science and Engineering Ethics 11, 373-385 (2005).

63. Harris, J. C. E., Pritchard, M. S., Rabins, M. J., James, R. \& Englehardt, E. Engineering Ethics: Concepts and Cases. (Cengage Learning, 2013).

64. Edwards, A. R. The sustainability revolution: Portrait of a paradigm shift. (New Society Publishers, 2005).

65. Bridger, J. C. \& Luloff, A. E. Toward an interactional approach to sustainable community development. Journal of Rural Studies 15, 377-387 (1999).

66. Lucena, J. C. \& Rolston, J. Invisible Innovators: How low-income students's agency might connect engineering/design for development with social justice. in (2014).

67. Kahan, D., Jenkins-Smith, H. \& Braman, D. Cultural cognition of scientific consensus. Journal of Risk Research 14, 147-174 (2011).

68. ABET. Criteria for Accrediting Engineering Programs. (2004). 